Belleri, A., Moaveni, B. and Restrepo, J. I. (2014), Damage assessment through structural identification of a three-story large-scale precast concrete structure. Earthquake Engng. Struct. Dyn., 43: 61-76. doi: 10.1002/eqe.2332 


\title{
Damage Assessment through Structural Identification of a Three-story Large- scale Precast Concrete Structure
}

\author{
Andrea Belleri ${ }^{1}$, Babak Moaveni ${ }^{2}$, and José I. Restrepo ${ }^{3}$
}

\begin{abstract}
This paper investigates the damage assessment of a three story half scale precast concrete building resembling a parking garage through structural identification. The structure was tested under earthquake type loading on the NEES Large High-Performance Outdoor Shake Table at the University of California San Diego in 2008. The tests provide a unique opportunity to capture dynamic performance of precast concrete structures built under realistic boundary conditions. The effective modal parameters of the structure at different damage states have been identified from white-noise and scaled earthquake test data with the assumption that the structure responded in a quasi-linear manner. Modal identification has been performed using the deterministic-stochastic subspace identification method based on the measured input-output data. The changes in the identified modal parameters are correlated to the observed damage. In general, the natural frequencies decrease and the damping ratios increase as the structure is exposed to larger base excitations, indicating loss of stiffness, development/propagation of cracks and failure in joint connections. The analysis of the modal rotations and curvatures allowed to localize shear and flexural damage respectively and to check the effectiveness of repair actions.
\end{abstract}

\section{Keywords:}

Shake-table testing, modal analysis, deterministic-stochastic subspace identification, damage detection, precast concrete structure

\section{INTRODUCTION}

With recent advances in sensor technology, computational power and system identification methodologies, structural health monitoring (SHM) has received increased attention in the civil engineering community as a potential tool for damage diagnosis and prognosis (i.e., estimating the remaining life) of structures. The ASCE SEI Committee on Structural Identification has recently prepared a state-of-art report in with the title of "Structural Identification of Constructed Facilities: Approaches, Methods and Technologies for Effective Practice of St-Id" [1]. The report underlined the existing gap between applications of SHM methods to small-scale models in the laboratory and applications to real-world complex structures. Vibration-based SHM methods are among the SHM methods successfully applied for damage identification of realworld structures. These methods involve conducting dynamic tests on the structure during its

\footnotetext{
${ }^{1}$ Post-doctoral researcher, Dept. of Engineering, University of Bergamo, Italy.

${ }^{2}$ Corresponding author. Assistant Professor, Dept. of Civil and Environmental Engineering, Tufts University, Medford, MA 02155. Telephone: 617-627-5642; Fax: 617-627-3994; Email: babak.moaveni@tufts.edu.

${ }^{3}$ Professor, Dept. of Structural Engineering, University of California, San Diego.
} 
lifetime. Changes in identified dynamic characteristics such as modal parameters of structures are commonly used in vibration-based SHM methods for the purpose of condition assessment and damage identification of structures. Extensive literature reviews on damage identification methods based on changes in dynamic properties are provided in [2-9]. This paper, presents an application of a vibration-based SHM for damage assessment of a three-story large-scale precast structure. System and damage identification of support-excited structures have been the topic of several recent studies. Kim and Lynch [10] proposed system identification for estimating the physical parameters of shear buildings from input-output or output-only data and verified the proposed method for a support-excited scaled single-bay steel frame. Hsu and Loh [11] proposed a damage detection method based on the changes in the frequency response function of the same $1 / 4$-scale six-story steel frame before and after the occurrence of the damage. Loh et al. [12] applied nonlinear system identification to estimate the stiffness and strength degradation in a reinforced concrete structure. Arici and Mosalam [13] used state-space identification methods for modal identification of seismically excited concrete bridges. Previous efforts have been made to identify damage and loss of prestress on single precast concrete elements [14-16] based on structural dynamic responses. However, to the authors' knowledge, no damage assessment study is available in the literature on large scale precast concrete buildings before and after earthquakes.

A three-story half-scale precast concrete building resembling a parking garage, was tested on the NEES Large High-Performance Outdoor Shake Table at the University of California San Diego in May-July 2008 as the last phase of a joint project between University of Arizona, Lehigh University and University of California San Diego. The aim of the research project was the investigation of the flexural and shear behavior of different types of precast concrete floors under seismic loading in order to validate nonlinear finite element computer models, structural analysis, and to define a design methodology for precast concrete diaphragms [17]. The testing program on this precast concrete structure provides vibration data from a complex large scale system with actual construction practices and half scale details under realistic boundary conditions that cannot be easily reproduced by numerical simulations or small-scale laboratory models. The specimen was subjected to scaled historical ground motions to simulate design seismic loading. Between these large amplitude seismic tests the structure was subjected to white-noise and low amplitude earthquake excitations during which it responded as a quasilinear system with modal parameters (natural frequencies, mode shapes and damping ratios) changing as a result of damage and of retrofitting. In this study, modal parameters of the structure at selected damage states are identified using the deterministic-stochastic subspace identification method [18] based on measured input and output acceleration data. The identified results are compared to the damage observed visually on the specimen.

Next section briefly introduces the building geometry, instrumentation layout and test sequence, whose further information can be found elsewhere [19]. Then the data cleansing process, the system identification method, and the results are reported. Finally, the obtained results are compared with the observed damage. 


\section{SHAKE-TABLE TESTS}

\section{Structure Description}

The structure tested on the shake table had a $17.07 \mathrm{~m}$ long by $4.88 \mathrm{~m}$ wide $(56 \times 16 \mathrm{ft})$ rectangular plan and a story height of $1.98 \mathrm{~m}(6.5 \mathrm{ft})$. The specimen was wider than the shake table platen's footprint (Figures 1 and 2), therefore a rigid building foundation was provided in order to transfer the seismic motion to the whole structure without motion amplification. The ends of the rigid foundation were outfitted with massive outrigger beams in order to balance building overturning; two hydrostatic slider bearings, with low coefficient of friction $(<1 \%)$, were employed on each outrigger beam to minimize input energy disturbance.

Three different precast floor systems were adopted at each level, namely a composite doubletee diaphragm at the first floor, non-composite hollow-core at the second and pretopped doubletee diaphragm at the third. Figure 3 shows the cross sections of the floor units and the connection with adjacent elements. Additional details on the connections geometry and position

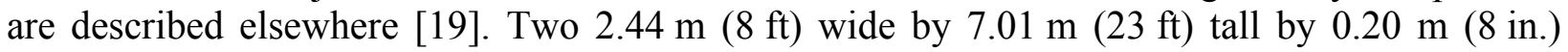
thick precast walls were placed at the North and South edges of the structure as the primary lateral force resisting system.

The walls were designed and detailed to act as rocking and hybrid walls [20], with their cross sections and schematic behavior shown in Figure 4. These types of systems adopt gravity loading supplemented with unbonded post-tensioned tendons (PT) to ensure self-centering response. A rocking wall displays a nonlinear elastic response under lateral loading with a distinct stiffness reduction in the lateral force-displacement response associated to the uplift of the wall base. A hybrid wall differs from a rocking wall because of the addition of energy dissipation (ED). Compared to traditional reinforced concrete walls, these systems accommodate the lateral displacement seismic demand by the development of a single concentrated opening at the base allowing wall rotation, instead of distributing flexural cracks at the plastic hinge region at the base of the wall. The base of the walls and the bedding mortar where they rest are appropriately detailed to delay the onset of structural damage such as spalling of the concrete.

In each wall of the tested structure, post tensioning was provided by two sets of five, $13 \mathrm{~mm}$ ( 0.5 in.) diameter, unbonded tendons while energy dissipation was provided by $22 \mathrm{~mm}(7 / 8 \mathrm{in}$.) diameter ASTM A 706 reinforcing bars, placed across the wall-foundation joint. Five bars were grouted in the wall footing beam before wall erection and placed in ducts at the bottom of each walls. However, only bars $\mathrm{ED}_{2}$ and $\mathrm{ED}_{4}$ (Figure 4) were grouted in the wall to provide energy dissipation. Bars $\mathrm{ED}_{1}, \mathrm{ED}_{3}$ and $\mathrm{ED}_{5}$ were not grouted to the wall as they were designed as backup devices in the case of early failure of $\mathrm{ED}_{2}$ and $\mathrm{ED}_{4}$.

\section{Instrumentation}

A comprehensive array of sensors including 640 sensors was deployed on the test structure measuring accelerations, displacements or deformations, strains, and pressures. Only the accelerometers mounted on the floors and on the walls (Figure 5) in the direction of shaking were adopted in the system identification procedure. The other accelerometers deployed in the tests recorded base motions or local components of secondary elements not part of the lateral load resisting systems. Other measurement devices such as strain gages and displacement potentiometers provided local vibration response with lower frequency content. All measured data were collected at a sampling rate of $240 \mathrm{~Hz}$. 


\section{Input Ground Motions}

The test structure was subjected to 16 ground motion records of increasing intensity on the shake table in order to induce progressive damage in the specimen. The ground motion records were selected from historical earthquakes to represent low, moderate and high seismic hazards for three sites in the United States: Knoxville (Tennessee), Seattle (Washington) and Berkeley (California). The records were scaled to meet the Design Basis Earthquake (DBE) for the Knoxville (KNX), Seattle (SEA) and Berkeley (BER) sites. After completion of the DBE tests for the three sites, the building was subjected to the Maximum Considered Earthquake (MCE) for the Berkeley site (MCE-BER). Between the seismic tests, the building was subjected to lowamplitude white-noise base excitation (WN) and to small earthquake type loading (EQ-Ch) whose 5\% damping pseudo-acceleration response spectrum is shown in Figure 6.

Table 1 reports the shake table base excitations considered in the paper. In tests T1 to T6, the walls were acting as rocking walls, while in the following tests energy dissipation bars $\mathrm{ED}_{2}$ and $\mathrm{ED}_{4}$ (Figure 4) were grouted leading to a hybrid wall behavior. The table also shows the repair actions taken after damage occurred at the second and third floors [19].

\section{SYSTEM IDENTIFICATION}

\section{Deterministic-Stochastic Subspace Identification Method}

In this study, the deterministic-stochastic subspace identification (DSI) method [14] is used to extract the modal parameters of the test structure based on input-output data of the 28 tests listed in Table 1. The DSI is a parametric linear system identification method that "realizes" the system model in state-space from the input-output measurements directly. This method is robust to the input disturbance (state noise) as well as measurement noise because both terms are explicitly considered in its formulation. Numerical techniques such as QR factorization, singular value decomposition and least squares are used in this identification method.

Output-only system identification (or operational modal analysis) methods have been successfully applied for system identification of large-scale civil structures [21-24]. These methods are based on the assumption of a broadband (ideal white-noise) input excitation. It is worth noting that some output-only system identification methods can still provide reasonable results when input excitation is a "colored" signal (slight deviation from white-noise) [25]. However, in the current application the input excitation has a strong spectral peak at the oilcolumn frequency of the shake table actuators which would not result in accurate estimation of modal parameters, due to deviation of the input excitations from broadband signals.

Before the application of the system identification procedure, data were filtered with a $2048^{\text {th }}$ order FIR filter with bandpass frequency $0.2-33 \mathrm{~Hz}$. After filtering, the data were downsampled to $120 \mathrm{~Hz}$ and the signals are corrected for the filter delays. Only the data from accelerometers in the shaking direction (East-West) were used for modal identification since the vertical and transversal measurements are significantly smaller. The acceleration at the base of North wall is considered as the input excitation record. Note that the measured accelerations at the base of North and South walls are very close and result in similar modal parameters. A total of 48 sensors are used in the system identification procedure consisting of 6 on the walls ( 3 on each wall at floor levels) and 42 on the floors (14 per floor). For each dynamic test, an inputoutput Hankel matrix was formed including 22 block rows (except for tests T23 and T26 where 
13 block rows were used) with 49 rows in each block (1 input and 48 output channels) and 13758 (WN), 14158 (EQ-Ch), 2178 (KNX), 2257 (SEA) and 1268 (BER and BER-MCE) columns using the filtered and down-sampled data.

\section{System Identification Results}

Based on the stabilization diagrams, three vibration modes of the structure can be consistently identified as stabilized modes. Figure 7 shows the stabilization diagram for test T1. It can be observed that the three lowest vibration modes become stable at 5.29, 8.01 and 10.59 Hz. Figure 7 shows in compass plots the identified complex-valued mode shapes for these three vibration modes. It can be observed that the mode shape components for these three modes are almost collinear indicating that these modes are classically damped. The first and third vibration modes are longitudinal while the second is torsional (Figure 8). The motions of floors and walls in mode shapes obtained from low intensity tests appear disconnected due to vertical slotted connections (Figure 9). This type of connection has been chosen to allow horizontal shear transfer and avoid the introduction of out of plane forces in the floor due to wall uplift as a consequence of wall base rotation. Although the connections purpose is to provide horizontal shear transfer, there is a limited amount of slackness which allowed free horizontal relative movements between the walls and the floor edges during low intensity tests as recorded from displacement transducers.

Table 2 summarizes the identified natural frequencies, damping ratios $(\xi)$ and MAC (Modal Assurance Criterion) values for the three identified modes based on different test data. The identified modal parameters correspond to those of an equivalent linear system with stiffness equal to "effective" stiffness of the nonlinear structure over the considered excitation [26, 27].

The MAC values are computed between identified mode shapes and their counterpart identified based on T1 test data. Test T19 was not considered in the identification procedure due to data acquisition system problems. From this table, it can be observed that:

(1) Modal parameters show significant changes after each of the large-amplitude earthquake tests (T3, T6, T9, T13, T17, T20, T23, T26). In general the natural frequencies decrease and the damping ratios increase as the structure is exposed to larger base excitations (except during repairs shown as double lines in the table).

(2) Mode 1 is consistently identified during all tests, Mode 3 is identified during all but one test, and Mode 2 is missed during six tests.

(3) Natural frequencies identified based on large-amplitude earthquake tests are significantly smaller than those identified from the low-amplitude tests immediately before or after the earthquakes. This is due to the fact that the test structure will behave highly nonlinear during parts of these large-amplitude tests.

(4) In general the MAC values for all three modes are in a reasonable range except for tests which exhibited third floor mid-span flexural failure.

\section{DISCUSSION OF RESULTS}

Although the system identification method adopted in the present study, deterministic-stochastic subspace identification (DSI), is appropriate for structures acting as linear system, it still provides reasonably accurate estimates of modal parameters when applied to moderately 
nonlinear structures [26, 27]. The accuracy of the realized state-space models have been investigated for all the tests. The measured responses are compared with those simulated by identified state-space models. During the parametric system identification process used, the state space matrices $(\mathbf{A}, \mathbf{B}, \mathbf{C}, \mathbf{D})$ are estimated. Having the input $(\mathbf{u})$, the output $(\mathbf{y})$ is simulated using the state-space formulation of a linear dynamic system for discrete-time:

$$
\left\{\begin{array}{l}
\mathbf{x}((k+1) \Delta t)=\mathbf{A x}(k \Delta t)+\mathbf{B u}(k \Delta t) \\
\mathbf{y}(k \Delta t)=\mathbf{C x}(k \Delta t)+\mathbf{D u}(k \Delta t)
\end{array}\right.
$$

where $\Delta t$ is the constant sampling time and $k=0,1,2, \ldots, n$.

From this comparison, not shown here, it is observed that:

(1) In general the simulated responses are in good agreement with the measured data especially for white-noise base excitation (e.g. T1) and low-amplitude earthquake base excitation (e.g. $\mathrm{T} 2)$.

(2) The simulated floor accelerations are in closer agreement with their measured counterparts than that for the wall accelerations.

(3) The difference between simulated and measured accelerations is significantly larger for all moderate and large amplitude earthquakes due to higher structural nonlinearity.

The natural frequencies identified from moderate and large amplitude earthquakes data (KNX, SEA, BER and MCE-BER tests) are in general lower than those obtained from lower amplitude tests due to the larger nonlinearity of the former. In addition, higher modal damping ratios are associated to higher amplitude base excitations, because the system identification method considers the hysteretic energy dissipation as viscous in a linear equivalent system. For this reason, damping in the context of this paper should be understood as equivalent, and its magnitude should not be interpreted as one that should be used in nonlinear time-history analysis. The structure nonlinear response for higher amplitude ground motions is confirmed by the base shear versus mid-span roof displacement hysteretic plots (Figure 10), where the curves exhibit the elastic-bilinear and flag shape hysteresis typical of rocking (T3) and hybrid walls (T20, T23 and T26), respectively.

Changes in the identified modal parameters are correlated with the observed damage in the structure. Reduction of the identified natural frequencies and/or increase of damping ratios indicate loss of stiffness, development/propagation of cracks and/or yielding and failure in precast joint connections. In addition, changes in the mode shapes point to the location of damage. No relevant damage was detected in damage states S1.1 and S1.2. For damage state S2.1, the mode shape plots (Figure 11) allowed to localize damage at mid-span of third floor occurred during Seattle DBE, test T9, where the flexural chords and the shear keys of the pretopped diaphragm failed (Figure 12). The repair actions consisted in casting discrete reinforced concrete curbs at the East and West sides of the $3^{\text {rd }}$ floor, connected each other by slug welding of the headed steel reinforcing bars for flexure retrofit and placing a new shear key for shear retrofit Figure 13. Figure 14 shows the mode shapes after repair. Damage at mid-span of second floor was not repaired because it went unnoticed due to the embedment in the concrete topping of reinforcing bars and shear connections.

Several vibration-based damage identification methods are available in the literature which are based on the changes in natural frequencies, mode shapes, modal curvatures, modal strain 
energy or other modal parameters. Extensive review of the existing methodologies are shown for instance in [2-4]. The present paper considers changes in modal rotations [7] and curvatures [5, 6] for damage detection and localization. The fundamental basis for using modal rotations and curvatures in damage detection is that structural displacements of a linear elastic system can be described at every time instant as a linear combination of its mode shapes, therefore changes in modal rotations and curvatures could be related to changes in structural shear and bending stiffness from classical beam theory. In the present case study, shear and flexural floor damage can be localized analytically considering the floor as a deep beam and applying Timoshenko beam theory [28]. From Timoshenko's theory governing equations and from basic calculus, the relevant equations for damage detection are:

$$
\begin{gathered}
\frac{M(x)}{E I}=-\frac{\partial^{2} v}{\partial x^{2}}-\frac{1}{k G A} \frac{\partial^{2}}{\partial x^{2}}\left(E I \frac{\partial^{2} u}{\partial x \partial y}\right)=-\frac{\partial^{2} v}{\partial x^{2}}-\frac{q(x)}{k G A} \\
\frac{V(x)}{k G A}=\left(\frac{\partial u}{\partial y}+\frac{\partial v}{\partial x}\right)
\end{gathered}
$$

where $E$ and $G$ are the Young and shear modulus, $A$ and $I$ are the section area and moment of inertia, $v$ is the deflection along East-West direction (y-axis), $x$ and $u$ are the position and deflection along North-South direction (x-axis), $q(x)$ is the external lateral load, $M(x)$ and $V(x)$ are the corresponding bending moment and shear and $k$ is the shear correction factor arising from Timoshenko assumption of constant strain distribution through beam thickness. In the case of the considered precast floor units with discrete joints it is possible to define an equivalent beam model [29] for the geometry and material data definition: $A$ and $I$ are associated to the cross section made by double-tee flange plus concrete topping for the first floor, concrete topping for the second floor and double-tee pre-topped flange for the third floor while $E$ and $G$ are evaluated as equivalent properties taking into account the influence of steel reinforcing bars and connectors.

Considering the precast floors of the selected case study as a statically determined structure in the floor plane [20] and assuming the same lateral load $q(x)$ (inertia forces derived from mode shapes) before and after damage, therefore the same internal force distribution and bending moment $M(x)$, equation (2) allows to associate damage related changes in flexural stiffness (EI) and shear stiffness $(k G A)$ to variations of $\partial^{2} v / \partial x^{2}$. Being the contribution of shear stiffness to $\partial^{2} v / \partial x^{2}$ less than $16 \%$ in the damaged region of the selected case study, variations of modal curvatures $\partial^{2} v / \partial x^{2}$ are mainly related to flexural damage. In the case of Euler-Bernoulli beams $\partial^{2} v / \partial x^{2}$ is totally associated to flexural damage. Equation (3) allows detection of shear damage as variations of shear stiffness from changes in modal rotations. Being the sensors suitable for system identification recording structural accelerations along y-axis, no information is available on modal shape components along $\mathrm{x}$-axis $(u)$ and therefore the contribution of $\partial u / \partial y$ to shear damage could not be considered; besides this, in the present case study the shear damage in the second and third floors, i.e. failure of shear mechanical connections between adjacent floor units, occurred at the floor mid-span, in a region where the first mode shape $\mathrm{x}$-axis component is zero for symmetry.

The modal rotations, $\partial v / \partial x$, and curvatures, $\partial^{2} v / \partial x^{2}$, for the three floors in selected tests, T14, T15 and T18, corresponding to damage states S2.3, S2.4 and S2.5, respectively, are 
presented in Figure 15 along with those corresponding to the undamaged state S0, test T1. Modal rotations and curvatures are computed using central difference [5] and no smoothing technique is applied. Both modal rotations and curvatures are derived for the first mode shape. Similar observations are made from the modal rotation and curvature of the third vibration mode. Damage could be detected and localized from the discontinuities in rotation and curvature mode shape changes from the undamaged to damaged structure [5].

No damage is present in the first floor in accordance to visual observation. In the second floor it is possible to localize both flexure and shear damage at mid-span associated to discontinuities in the modal curvature and rotation plots. Only flexural repair was carried out before test T18 replacing buckled reinforcing bars on the floor East side with a new reinforced concrete curb (Figure 16). The flexural repair was not complete as indicated in the modal curvature plot for test T18, probably because damage occurred on the West side reinforcing bars as well. No shear repair was carried out because of lack of visual information, although this did not compromise the structural performance due to the low shear value in that region associated to the test setup. In the third floor both shear and flexural damage can be localized at mid-span in tests T14 and T15 in accordance to visual inspection (Figure 12). The repair actions, before test T18, consisted in placing continuous reinforced concrete curbs at the floor East and West sides for flexural repair and a reinforced concrete shear key across the mid-span joint for shear repair (Figure 17). In this case the retrofit measures were appropriate as indicated by continuous lines in the modal curvatures and rotations plots for test T18. It is worth noting that the considerations inferred by the modal rotations and curvatures analysis are only valid in terms of flexural and shear stiffness; no information is available regarding flexural and shear strength $[30,31]$.

\section{CONCLUSION}

This paper performs damage assessment through structural identification of a three story half scale precast concrete building resembling a parking garage tested under earthquake type loading on the NEES-UCSD Shake Table in 2008. The system identification was carried on based on the deterministic-stochastic subspace identification method. The effective modal parameters of the structure at different damage states show significant changes after each of the large-amplitude earthquake tests. In general the natural frequencies decrease and the damping ratios increase as the structure is exposed to larger base excitations. It is worth noting that the identified damping ratios in this study represent the system equivalent viscous damping ratios and cannot be used as the viscous component in nonlinear finite elements analyses because in nonlinear models hysteretic damping is explicitly taken into account by the nonlinear material behavior.

Changes in the identified modal parameters are correlated with the observed damage in the structure especially in the mid-span joint of the second and third floor. The analysis of the identified mode shapes allow to point to the location of damage. Specifically, localized changes in the first and second spatial derivatives of mode shapes, modal rotations and curvatures, indicate local losses of shear and bending stiffness, respectively. The discontinuity in modal rotations and curvatures allowed localizing both visually detected damage in the third floor midspan joint, and an undetected damage in second floor mid-span joint providing a useful tool for precast floor damage detection. It is also worth noting that in the case of floor diaphragms with deep beam geometry, using both translational and rotational modal components will provide more accurate estimation of damage in accordance with the Timoshenko beam theory. Another 
useful feature of modal rotations and curvatures analysis is the evaluation of the effectiveness of the repair actions, although only in terms of stiffness because no direct correlation between flexural and shear strengths and the identified effective modal parameters is observed [30, 31].

\section{ACKNOWLEDGEMENTS}

The authors wish to express their gratitude to the Precast/Prestressed Concrete Institute, the National Science Foundation, the Charles Pankow Foundation, and the George E. Brown Jr. Network for Earthquake Engineering Simulation and all the people involved in the DSDM project, particularly to Professor R.B. Fleischman at the University of Arizona who led the NSF project and to Dr. M.J. Schoettler at the University of California Berkeley. The first author greatly acknowledges the financial support of Fondazione Cariplo (Bergamo, Italy) under the FYRE mobility program. The opinions, findings, and conclusions expressed in the paper are those of the authors and do not necessarily reflect the views of the individuals and organizations involved in this project.

\section{REFERENCES}

1. ASCE Committee on Structural Identification of Constructed Systems. Methods and Technologies for Effective Practice of Structural Identification, a State-of-the-Art Report. ASCE, in press.

2. Doebling SW, Farrar CR, Prime MB. A summary review of vibration-based damage identification methods. The Shock and Vibration Digest; 1998; 30(2):99-105.

3. Sohn H, Farrar CR, Hemez FM, Shunk DD, Stinemates DW, Nadler BR. A review of structural health monitoring literature: 1996-2001. Technical Report, Los Alamos National Laboratory 2003; LA-13976-MS, Los Alamos, New Mexico, USA.

4. Fan W, Qiao P. Vibration-based Damage Identification Methods: A Review and Comparative Study. Structural Health Monitoring; 2011; 10(1):83-111.

5. Pandey AK, Biswas M, Samman MM. Damage detection from changes in curvature mode shapes. Journal of Sound and Vibration; 1991; 145(2):321-332.

6. Ratcliffe CP. Damage detection using a modified Laplacian operator on mode shape data. Journal of Sound and Vibration; 1997; 204:505-517.

7. Abdo MAB, Hori M. A numerical study of structural damage detection using changes in the rotation of mode shapes. Journal of Sound and Vibration; 2002; 251:227-239.

8. Carden EP, Fanning P. Vibration based condition monitoring: a review. Structural Health Monitoring; 2004; 3(4):355-377.

9. Farrar CR, Worden K. An introduction to structural health monitoring. Phil. Trans. R. Soc. A; 2007; 365:303-315.

10. Kim J, Lynch J P. Subspace System Identification of Support Excited Structures - Part II: Gray-box Interpretations and Damage Detection. Earthquake Engineering and Structural Dynamics; 2012; 41:2253-71. 
11. Hsu T-Y, Loh C-H. A frequency response function change method for damage localization and quantification in a shear building under ground excitation. Earthquake Engineering and Structural Dynamics; 2013; 42:653-668; DOI: 10.1002/eqe.2235.

12. Loh C-H, Mao C-H, Huang J-R, Pan T.-C. System identification and damage evaluation of degrading hysteresis of reinforced concrete frames. Earthquake Engineering and Structural Dynamics; 2011; 40:623-640. doi:10.1002/eqe.1051.

13. Arici Y, Mosalam KM. Modal Identification of Bridge Systems using State- space Methods. Structural Control and Health Monitoring; 2005; 12:381-404.

14. Kim JT, Yun CB, Ryu YS, Cho HM. Identification of prestress-loss in PSC beams using modal data. Structural Engineering and Mechanics; 2004; 17(3-4):467-482.

15. Unger JF, Teughels A, De Roeck G. System Identification and Damage Detection of a Prestressed Concrete Beam. Journal of Structural Engineering, ASCE; 2006; 132:16911698.

16. Franchetti P, Modena C, Feng MQ. Nonlinear Damping Identification in Precast Prestressed Reinforced Concrete Beams. Computer-Aided Civil and Infrastructure Engineering; 2009; 24:577-592.

17. Fleischman RB, Naito C, Restrepo J, Sause R, Ghosh SK, Wan G, Schoettler M, Cao L. Precast Diaphragm Seismic Design Methodology (DSDM) Project, Part 2: Research Program. PCI Journal; 2005; 50(6):14-31.

18. Van Overschee P, de Moore B. Subspace identification for linear systems. Kluwer Academic Publishers, Massachusetts, USA, 1996.

19. Schoettler MJ, Belleri A, Zhang D, Restrepo JI, Fleischman RB. Preliminary results of the shake-table testing for the development of a diaphragm seismic design methodology. $P C I$ Journal; 2009; 54(1):100-124.

20. Belleri A, Schoettler MJ, Restrepo JI, Fleischman RB. Dynamic behavior of rocking and hybrid cantilever walls in a precast concrete building. Accepted at ACI Structural Journal.

21. Brincker R, Kirkegaard PH. Editorial for the special issue on operational modal analysis. Mechanical Systems and Signal Processing; 2010; 24(5):1209-1212.

22. Peeters B, De Roeck GD. Stochastic system identification for operational modal analysis: A review. Journal of Dynamic Systems, Measurement, and Control; 2001; 123:659-667.

23. Moaveni B, He X, Conte JP, Restrepo JI, Panagiotou M. System identification study of a seven-story full-scale building slice tested on the UCSD-NEES shake table. Journal of Structural Engineering, ASCE; 2011; 137(6):705-717.

24. Moaveni B, Barbosa AR, Conte JP, Hemez FM. Uncertainty Analysis of System Identification Results Obtained for a Seven Story Building Slice Tested on the UCSDNEES Shake Table. Structural Control and Health Monitoring; 2013; DOI: $10.1002 /$ stc. 1577.

25. Moser P. Continuous monitoring of the Dowling Hall Footbridge, MS thesis, Department of Civil and Environmental Engineering, Tufts University, Medford, Massachusetts, 2010.

26. Moaveni B, Asgarieh E. Deterministic-stochastic subspace identification method for identification of nonlinear structures as time-varying linear systems. Mechanical Systems and Signal Processing; 2012; 31:40-55. 
27. Moaveni B, Barbosa AR, Panagiotou M, Conte JP, Restrepo JI. Uncertainty analysis of identified damping ratios in nonlinear dynamic systems. Proc. of International Modal Analysis Conference, Orlando, USA; 2009.

28. Timoshenko SP, Goodier JN. Theory of Elasticity. McGraw-Hill, New York, 3rd edition, 1970.

29. Zheng W, Oliva MG. A practical method to estimate elastic deformation of precast pretopped double-tee diaphragms. PCI Journal; 2005; 50(2):44-55.

30. Moaveni B, Stavridis A, Lombaert G, Conte JP, Shing PB. Finite element model updating for assessment of progressive damage in a three-story infilled RC frame. Journal of Structural Engineering, ASCE; 2012; in press.

31. Moaveni B, He X, Conte JP, Restrepo JI. Damage identification study of a seven-story fullscale building slice tested on the UCSD-NEES shake table. Structural Safety; 2010; 32(5):347-356. 
TABLES

Table 1 - Base excitation tests performed on the specimen

\begin{tabular}{|c|cc|}
\hline Test ID & Input Type & Damage State \\
\hline T1 & WN & S0 \\
T2 & EQ-Ch & S0 \\
T3 & KNX & \\
T4 & WN & S1.1 \\
T5 & EQ-Ch & S1.1 \\
T6 & KNX \\
\hline \hline \multicolumn{2}{|c|}{ Grouting of energy dissipation bars } \\
\hline T7 & WN & S1.2 \\
T8 & EQ-Ch & S1.2 \\
T9 & SEA \\
T10 & 3WN & S2.1 \\
\hline \hline \multicolumn{3}{|c|}{$3^{\text {rd }}$ floor repair 1 } \\
\hline \hline T11 & WN \\
T12 & EQ-Ch & S2.2 \\
T13 & SEA \\
T14 & 3WN \\
\hline \hline
\end{tabular}

\begin{tabular}{|c|cc|}
\hline Test ID & Input Type & Damage State \\
\hline \multicolumn{3}{|c|}{ 3 $^{\text {rd }}$ floor repair 2 } \\
\hline T15 & WN & S2.4 \\
T16 & EQ-Ch & S2.4 \\
T17 & SEA \\
\hline \multicolumn{2}{|c|}{$2^{\text {nd }}$ floor repair 1 and $3^{\text {rd }}$ floor repair 3 } \\
\hline \hline T18 & WN & S2.5 \\
T19 & EQ-Ch & S2.5 \\
T20 & SEA & \\
T21 & WN & S2.6 \\
T22 & EQ-Ch & S2.6 \\
T23 & BER & \\
T24 & WN & S3 \\
T25 & EQ-Ch & S3 \\
T26 & BER-MCE & \\
T27 & WN & S4 \\
T28 & EQ-Ch & S4 \\
\hline
\end{tabular}


Table 2. Identified modal parameters during different tests/damage states

\begin{tabular}{|c|c|c|c|c|c|c|c|c|c|}
\hline \multirow{2}{*}{$\begin{array}{l}\text { Test } \\
\text { No. }\end{array}$} & \multicolumn{3}{|c|}{ Mode 1} & \multicolumn{3}{|c|}{ Mode 2} & \multicolumn{3}{|c|}{ Mode 3} \\
\hline & Freq [Hz] & $\xi[\%]$ & MAC & Freq [Hz] & $\xi[\%]$ & MAC & Freq [Hz] & $\xi[\%]$ & MAC \\
\hline $\mathrm{T} 1$ & 5.29 & 5.3 & 1.00 & 8.01 & 5.1 & 1.00 & 10.59 & 7.2 & 1.00 \\
\hline $\mathrm{T} 2$ & 5.36 & 5.6 & 1.00 & 8.12 & 5.9 & 0.91 & 11.28 & 6.1 & 0.99 \\
\hline T3 (EQ) & 3.56 & 7.5 & 0.96 & 6.30 & 11.9 & 0.54 & 8.93 & 2.2 & 0.94 \\
\hline $\mathrm{T} 4$ & 4.43 & 8.8 & 0.99 & 7.14 & 6.0 & 0.87 & 8.80 & 8.3 & 0.93 \\
\hline T5 & 4.58 & 10.3 & 1.00 & 7.51 & 5.5 & 0.95 & 8.97 & 7.9 & 0.94 \\
\hline T6 (EQ) & 3.50 & 13.3 & 0.97 & - & - & - & 8.58 & 2.8 & 0.91 \\
\hline $\mathrm{T} 7$ & 4.55 & 8.5 & 1.00 & 7.22 & 5.4 & 0.95 & 8.88 & 9.6 & 0.98 \\
\hline $\mathrm{T} 8$ & 4.65 & 8.5 & 1.00 & 7.64 & 7.2 & 0.86 & 9.49 & 6.3 & 0.98 \\
\hline T9 (EQ) & 2.87 & 13.9 & 0.92 & 4.44 & 8.2 & 0.60 & 8.49 & 21.2 & 0.72 \\
\hline $\mathrm{T} 10$ & 2.58 & 10.1 & 0.91 & - & - & - & 6.27 & 10.2 & 0.75 \\
\hline $\mathrm{T} 11$ & 4.06 & 7.1 & 0.98 & - & - & - & 7.94 & 7.9 & 0.91 \\
\hline $\mathrm{T} 12$ & 4.06 & 7.5 & 0.99 & 6.83 & 5.8 & 0.85 & 8.17 & 9.3 & 0.93 \\
\hline T13 (EQ) & 2.46 & 12.2 & 0.97 & - & - & - & 8.63 & 5.6 & 0.71 \\
\hline $\mathrm{T} 14$ & 2.72 & 10.3 & 0.92 & - & - & - & - & - & - \\
\hline $\mathrm{T} 15$ & 3.36 & 8.2 & 0.97 & 6.18 & 5.0 & 0.88 & 7.06 & 8.3 & 0.92 \\
\hline T16 & 3.42 & 7.4 & 0.96 & 6.09 & 4.8 & 0.84 & 7.29 & 8.0 & 0.93 \\
\hline T17 (EQ) & 2.34 & 16.1 & 0.95 & - & - & - & 7.68 & 6.2 & 0.84 \\
\hline T18 & 3.81 & 7.8 & 0.97 & 6.27 & 6.7 & 0.85 & 7.12 & 8.7 & 0.89 \\
\hline T20 (EQ) & 2.57 & 10.4 & 0.96 & 4.18 & 6.1 & 0.86 & 6.89 & 7.1 & 0.93 \\
\hline $\mathrm{T} 21$ & 3.16 & 8.7 & 0.96 & 5.99 & 10.3 & 0.81 & 6.39 & 9.2 & 0.93 \\
\hline T22 & 3.38 & 7.4 & 0.94 & 6.11 & 6.7 & 0.85 & 6.63 & 7.5 & 0.87 \\
\hline T23 (EQ) & 1.94 & 10.6 & 0.94 & 3.47 & 1.4 & 0.87 & 5.96 & 6.6 & 0.69 \\
\hline $\mathrm{T} 24$ & 2.84 & 8.2 & 0.91 & 5.07 & 5.5 & 0.86 & 6.21 & 9.0 & 0.93 \\
\hline $\mathrm{T} 25$ & 3.03 & 8.1 & 0.91 & 5.21 & 3.5 & 0.87 & 6.66 & 6.8 & 0.89 \\
\hline T26 (EQ) & 1.63 & 17.6 & 0.93 & - & - & - & 6.47 & 10.1 & 0.66 \\
\hline $\mathrm{T} 27$ & 1.22 & 21.2 & 0.85 & 2.36 & 13.3 & 0.88 & 6.02 & 7.6 & 0.87 \\
\hline T28 & 1.18 & 19.2 & 0.88 & 1.96 & 8.1 & 0.89 & 6.36 & 4.8 & 0.85 \\
\hline
\end{tabular}

